\title{
Reflets
}

Revue ontaroise d'intervention sociale et communautaire

\section{Le Programme régional des soins palliatifs de Sudbury : une réussite à souligner et à protéger}

\section{Guy Racine}

Volume 5, numéro 2, automne 1999

La santé des francophones de l’Ontario

URI : https://id.erudit.org/iderudit/026286ar

DOI : https://doi.org/10.7202/026286ar

Aller au sommaire du numéro

Éditeur(s)

Reflets : Revue ontaroise d'intervention sociale et communautaire

ISSN

1203-4576 (imprimé)

1712-8498 (numérique)

Découvrir la revue

Citer cet article

Racine, G. (1999). Le Programme régional des soins palliatifs de Sudbury : une réussite à souligner et à protéger. Reflets, 5(2), 268-269.

https://doi.org/10.7202/026286ar

Tous droits réservés (C) Reflets : Revue ontaroise d'intervention sociale et communautaire, 1999
Ce document est protégé par la loi sur le droit d'auteur. L’utilisation des services d’Érudit (y compris la reproduction) est assujettie à sa politique d'utilisation que vous pouvez consulter en ligne.

https://apropos.erudit.org/fr/usagers/politique-dutilisation/ 


\section{Le Programme régional des soins palliatifs de Sudbury : une réussite à souligner et à protéger}

G uy Radine

R etraité, Sudbury

Parmi les programmes et lesservices de santé offertsà la population de la région de Sudbury, il en est un qui mérite une mention particulière tant par l'efficacité de son organisation que par la qualité du «caring »qu'on y exerce et c'est le Programme régional des soins palliatifs.

Lancé en 1987, ce programme qui fait l'envie de plusieurs régions, a été le premier du genre dans le $\mathrm{N}$ ord-est ontarien. Jusqu'en octobre 1998, il avait formé au moins de 461 bénévoles et aidé plus de 1330 familles. M ême si tous les bénévoles, ayant bénéficié de la formation, ne se sont pas impliqués directement auprès de clients, le seul fait d'être sensibilisés aux multiples aspects dessoins palliatifs et d'avoir pu profiter d'une formation holistique de qualité, donnée par une équipe multidisciplinaire, valait amplement les efforts déployés par les fondateurs et les responsables actuels du programme.

En plusd'assurer la formation des bénévoles et la coordination des services auprès des familles, les responsables du programme offrent leur collaboration et jouent souvent un rôle de leadership dans différents domaines de la vie communautaire. Par exemple, certain s présentent, à l'occasion, des ateliers dans la communauté. De plus, le programme offre l'opportunité aux étudiants des collèges et des universités de poursuivre un stage de formation. 
Cependant, une ombre plane. M algré son succès et sa nécessité, la survie du programme régional des soins palliatifs de Sudbury est menacée. $Q$ uand nous voyons les coupures de budget faites par les gouvernements dans les services sociaux et de santé, nous sommes en droit de nous demander si un tel programme peut survivre et jusqu'à quand? II ne s'agit pas d'une question théorique puisqu'il y a quelques mois, la rumeur circulait sur sa disparition prochaine, faute de fonds.

Sans ce programme, qu'adviendra-t-il des nombreux malades dont la qualité de vie s'est améliorée grâce à la présence de bénévoles adéquatement formés et soutenus par un organisme bien structuré? Q ue deviendrons-nous quand notre tour viendra d'avoir besoin non seulement de soins professionnels, mais aussi et surtout d'une présence que, peut-être, nos proches, malgré tout leur amour et leur bonne volonté, ne pourront plus nous donner?

En coupant dans les budgets des services sociaux et de santé, les gouvernements comptent de toute évidence sur les membres des familles et les bénévoles pour prendre la relève, mais encore faudrait-il leur donner les moyens de le faire? Se soustraire à cette obligation, c'est gouverner à courte vue, c'est mal gouverner. Les programmes de soins palliatifs sont devenus nécessaires dans l'organisation d'un système de santé cherchant à répondre aux besoins d'une société de plus en plus vieillissante. II faut donc développer des stratégies qui permettront à ces programmes de rendre un service efficace et de qualité. Pour cela, il faut:

- procéder à la reconnaissance officielle de ces programmes et définir leur rôle dans le système de santé;

- faciliter l'accès à une formation de qualité (cours, colloque, etc.) et,

- soutenir concrètement la collaboration entre les programmes déjà existants.

Bien évidemment, il faut réaliser tout cela en évitant d'étouffer la spontanéité et la bonne volonté des bénévoles qui sont et doivent demeurer le fer de lance de tels programmes. 